\title{
Papéis sociais de gênero na velhice: o olhar de si e do outro
}

\author{
Social roles of gender in the olg age: the look of yourself and of the other \\ Papeles sociales de género en la vejez: la mirada propia y la del otro
}

\author{
Maria das Graças Melo Fernandes \\ 'Universidade Federal da Paraíba. Departamento de Enfermagem Médico-Cirúrgica. João Pessoa, PB
}

Submissão: 12/12/2008

Aprovação: 10/08/2009

\section{RESUMO}

Este estudo objetivou apreender a auto e a heteropercepção de homens e mulheres idosos acerca dos papéis sociais de gênero na velhice. O material empírico foi captado por meio de uma oficina de reflexão, envolvendo seis homens e dez mulheres Que aceitaram participar da pesquisa. Os dados foram examinados através da técnica de análise de discurso e ancorados no referencial de gênero. Os achados demonstram que os idosos demandam, tanto para si como para o outro (do sexo oposto), o exercício de papéis sociais determinados por padrões verificados na sociedade sexista, estabelecidos a partir das relações efetuadas entre os domínios do público e do privado, sendo o masculino associado ao mundo público, e o feminino, ao domínio da casa.

Descritores: Gênero; Idoso; Papel de gênero; Velhice.

\section{ABSTRACT}

This study had the objective to collect the self and the others perception of elderly men and women about the social roles of gender in the extent of the old age. The empirical material was captured by a workshop of reflection, involving six men and ten women who accept to be on the research. The data was examined by the technical of speech analysis, being based on the gender respect. The discoveries demonstrate that the elderly demand, as for themselves as for the other (of the opposite sex), the exercise of social roles certain by verified standards in the extend of the sexist society, established starting from the made relationships between the public and the private domains, being the masculine associated to the public world, and the feminine, to the house domain.

Descriptors: Gender; Elderly; Gender role; Old age.

\section{RESUMEN}

Este estudio objetivó aprehender la auto y la heteropercepción de hombres y mujeres ancianos acerca de los papeles sociales de género en la vejez. El material empírico fue captado por medio de un taller de reflexión, envolviendo seis hombres y diez mujeres Que aceptaron participar de la investigación. Los datos fueron examinados a través de la técnica de análisis de discurso y fundamentados en el referencial de género. Los resultados demuestran que los ancianos demandan, tanto para sí como para el otro (del sexo opuesto), el ejercicio de papeles sociales determinados por modelos verificados en la sociedade sexista, establecidos a partir de las relaciones efectuadas entre los dominios de lo público y de lo privado, siendo el masculino asociado al mundo público, y el femenino, al dominio del hogar.

Descriptores: Género; Anciano; Papel de género; Vejez. 


\section{INTRODUÇÃO}

A categoria gênero incorpora atributos e funções - socialmente construídos - Que configuram diferenças e inter-relações entre os sexos, Que vão além do biológico. Assim, ser homem ou ser mulher implica a incorporação desses atributos e funções, como forma de representar-se, valorizar-se e atuar numa determinada cultura(1).

Com esse mesmo entendimento sobre o assunto, Labourie e Locoh $^{(2)}$, ao discutirem o conceito de gênero, assinalam Que este conceito reforça a idéia de Que as diferenças biológicas de sexo são acompanhadas das diferenças de estatutos, de papéis, de responsabilidades e do lugar dos homens e das mulheres em todos os setores da sociedade e em todos os níveis, mas, igualmente, naquilo que é característico (ou Que se espera Que seja) do comportamento e das atitudes dos homens e das mulheres no seio da sociedade.

As expectativas sociais e a construção econômica, política, social, histórica, dos papéis masculino e feminino têm importância na formação da identidade de gênero - sentimento que indivíduos de ambos os sexos possuem em relação ao seu pertencimento a um ou outro sexo ${ }^{(3)}$. Essa construção influi no modo como os seres humanos elaboram suas escolhas e as experienciam e atribuem significados ao seu existir.

Com as intensas e aceleradas mudanças sócio-políticoeconômicas ocorridas na contemporaneidade, cada homem e cada mulher foi e continua sendo protagonista, espectador e autor de rupturas e transformações nos costumes e estilos de vida, atingindo cada um em diferentes gerações. A geração mais velha, por exemplo, experimentou, por maior espaço temporal, relações de poder e também naturalizou, mais intensamente, noções sobre papéis masculino/feminino calcadas num modelo tradicional de relações de gênero, em que havia o exercício da autoridade dos homens sobre as mulheres e os filhos no seio das famílias, ou seja, vivenciou uma assimetria relacional, o Que pode influenciar, também de modo diferencial, o modo do idoso perceber e vivenciar sua velhice, conforme a marca do seu gênero ${ }^{(4-5)}$.

Visando clarificar essa realidade em nosso contexto sociocultural, objetivamos, neste estudo, apreender de homens e mulheres idosos sua auto e heteropercepção acerca dos papéis sociais de gênero no âmbito da velhice, cabendo destacar Que o conceito de gênero transcende o mero desempenho de papéis sexuais estabelecidos pela sociedade, mas institui a identidade do sujeito ${ }^{(6)}$. Assim sendo, não pode ser entendido como sexo, como a condição natural das pessoas, mas como a representação de cada indivíduo em termos de uma relação social preexistente ao próprio indivíduo e predicada sobre a oposição conceitual e rígida (estrutural) dos dois sexos biológicos ${ }^{(7)}$.

\section{METODOLOGIA}

Este estudo, de natureza Qualitativa, foi efetivado no grupo de convivência de idosos Juventude Acumulada, localizado no bairro popular de Cruz das Armas, do município de João Pessoa-PB, no período de maio a junho de 2008. Quanto aos sujeitos participantes, estes compreenderam seis homens e dez mulheres, possuidores de poucos recursos sócio-econômicos e baixo nível instrucional, Que aceitaram, livremente, participar de tal investigação, mediante a assinatura do Termo de Consentimento Livre e Esclarecido, após receberem informações sobre seus objetivos, procedimentos operacionais e outras garantias éticas, como o respeito à sua privacidade e o sigilo das informações, conforme preconiza a Resolução 196/96 do CNS/MS ${ }^{(8)}$. Cabe ressaltar Que o projeto de pesquisa foi aprovado pelo Comitê de Ética em Pesquisa do Centro de Ciências da Saúde da Universidade Federal da Paraíba (protocolo $\mathrm{n}^{\circ}$. 0444).

Para a produção do material empírico, realizamos uma oficina de reflexão intitulada "masculino versus feminino", adaptada de Militão $0^{(9)}$. No primeiro momento dessa vivência coletiva, realizamos atividades de relaxamento físico e mental com vistas a proporcionar ao grupo um ambiente favorável para a expressão de seus pensamentos sobre o objeto de estudo.

Posteriormente, dividimos o grupo em dois sub-grupos: o masculino e o feminino. Nessa ocasião, convidamos os homens a completarem livremente a seguinte frase: "como homem idoso eu devo...”. Já as mulheres, concomitantemente, respondiam: "como mulher idosa eu devo...". Vencida essa etapa da atividade grupal, os homens passaram a se posicionar sobre "se eu fosse mulher idosa, eu deveria..." e, se eu fosse mulher idosa, eu não deveria...”. De modo oposto, as mulheres discorreram sobre "se eu fosse homem idoso, eu deveria..." e, se eu fosse homem idoso, eu não deveria...".

As informações suscitadas na oficina ora descrita foram abordadas por meio da técnica de análise de discurso proposta por Fiorin $^{(10)}$. Uma vez desvelado o posicionamento social dos idosos frente ao objeto investigado, ancoramos suas falas no referencial de gênero, considerando a perspectiva relacional.

\section{RESULTADOS E DISCUSSÃO}

Analisando o discurso do grupo masculino, observamos: como homem idoso, eu devo...

\section{...estar bem}

- me manter ativo, praticar esporte;

- tomar sempre uma vitamina, não dormir fora do horário;

- continuar vivendo, como se fosse novo;

- andar bem cheiroso;

- reconhecer que a velhice é mais um estado físico do que emocional.

\section{...ser o cabeça da família}

- ser o cabeça da família, trabalhar muito para manter a família;

- me manter atualizado sobre o que acontece com os de casa;

- administrar a casa.

... auxiliar a esposa

- ter carinho com minha esposa, Que já está doente;

- ajudar minha esposa, porQue já estou aposentado;

- realizar o trabalho de casa com minha esposa, para não ficar parado.

Conforme o exposto, verificamos que os homens idosos se sentem condicionados a estar bem, especialmente com a sua condição física, afastando, de algum modo, a velhice, mantendose ativos e cheirosos como se fossem jovens, esforçando-se, assim, para estarem incluídos no modelo hegemônico e estereotipado de juventude e de masculinidade considerado "normal" nas sociedades contemporâneas ocidentais. Além disso, mencionaram a importância de ser "o cabeça [chefe] da família", estabelecendo uma relação 
assimétrica de poder no âmbito familiar, naturalizando diferenças e desigualdades Que atestam sua identidade masculina e produzem a opressão das mulheres.

Apesar disso, observamos a preocupação de alguns idosos de auxiliar suas esposas, ou porQue elas já estão doentes, ou, em especial, porQue eles já estão aposentados e encontram nesse auxílio uma forma de ocupação. Nessa faixa etária, a situação do homem e da mulher tem algumas peculiaridades, conferidas pelo exercício de papéis desempenhados socialmente. $\mathrm{O}$ homem idoso, ao encerrar sua participação pública pelo trabalho mediante a aposentadoria retorna à área privada, isto é, a do lar, passando, então, a lidar com o dilema de descobrir uma nova identidade para enfrentar o universo discriminador, já conhecido pela mulher ${ }^{(11)}$.

Uma das difíceis tarefas dos homens Que envelhecem é a de refazer sua identidade de gênero frente à perda de vários dos atributos Que continuam a definir a masculinidade hegemônica (capacidade para o trabalho, força física, assertividade, potência sexual) ${ }^{(12)}$. Nesse contexto da velhice, em alguns casos, a convivência entre os sexos, com forças em equilíbrio, suscita a possibilidade de um novo relacionamento entre homem e mulher com base cooperativa e auxílio mútuo no enfrentamento comum da marginalização social, ou seja, a um redimensionamento dos papéis masculino e feminino. Essa situação tem contribuído para a redução da hierarquia entre os sexos nessa fase da vida.

lá as mulheres, ao completarem a assertiva: como mulher idosa, eu devo..., se posicionaram do seguinte modo:

\section{... cuidar da família e da casa}

- cuidar dos filhos e netos;

- como mãe e avó, ser boa conselheira; como esposa, cuidar bem do esposo;

- cumprir minha missão de avó;

- procurar ser compreensiva com a família;

- ajudar os meus filhos;

- ir à igreja, rezar pelos parentes;

- dar mais atenção à minha família;

- fazer minhas tarefas de casa;

- cuidar da minha casa;

- cuidar dos meus deveres como dona de casa.

\section{... cuidar da saúde}

- tenho de caminhar, ir ao médico, fazer exercícios;

- ser pontual com a medicação e alimentação;

- cuidar da saúde;

- caminhar, para ter uma saúde melhor;

- fazer tudo para zelar por minha saúde, me cuidar bastante; -não faltar às consultas médicas.

\section{... me comportar como mulher idosa}

-aprender a me comportar como mulher idosa;

-saber me vestir à caráter, ter uma conversa decente, conversa madura.

Considerando essas falas, verificamos Que as mulheres idosas, diferentemente dos homens, evidenciam como função principal de suas vidas a atividade cuidativa. O cuidar de si (principalmente para cuidar de outros) e, especialmente, o cuidado com a casa e com a família, constituem atividades Que para elas têm um importante significado social, sendo a base de sua construção de identidade como mulheres. Cabe destacar Que a distribuição de tarefas entre os sexos é entendida, em muitos sistemas culturais, a exemplo do nosso, como uma espécie de extensão das diferenças anatômicas (procriativas) entre os sexos ${ }^{(13)}$. Nesse cenário, o cuidado com a prole é Quase sempre destinado às mulheres.

Isso se justifica pela socialização Que as mulheres recebem, desde cedo, para reproduzirem e consolidarem os papéis Que as tornam responsáveis, Quase Que exclusivamente, pela provisão de cuidados aos outros no seio da família e pela priorização do outro nas ações morais. Para Neri ${ }^{(14)}$, as mulheres, em diferentes culturas, são mais envolvidas com a família do Que os homens, porque o exercício dos papéis femininos, ao longo do curso de vida, Ihes dá mais chance de desenvolver relações de intimidade do Que o exercício dos papéis masculinos permite aos homens.

Além disso, ao serem excluídas da participação na vida social e política, foi negada às mulheres, especialmente as Que hoje estão idosas, a oportunidade de adQuirirem autonomia e independência financeira, sendo o casamento, por muito tempo, a única oportunidade Que muitas delas tinham de adouirir segurança financeira e de se firmarem como seres obedientes às exigências sociais de mulher casada, mãe e dona-de-casa, papéis sociais Que também eram/são incorporados pelas mulheres como aqueles que faziam/fazem parte de seu ideal ${ }^{(15)}$. Vale salientar Que, nesse contexto, muitas vezes, a família era/é o lugar de severa desigualdade, e o privado, o lugar da privação.

Ampliando essa análise, Barros ${ }^{(16)}$ destaca Que a mulher idosa de hoje, no geral, está no último estágio de um continuum sempre ligado à esfera doméstica e do cuidado, não só porQue a grande maioria não teve uma vida profissional ativa, mas também porQue é a este mundo interno do lar, da família e da casa Que ela está ideologicamente vinculada. Nesse cenário da família tradicional, ainda subsiste a idéia de Que a mulher deve ser condicionada a assumir os papéis de esposa e mãe, colocando-os à frente de seus interesses individuais.

A partir do exposto, podemos salientar que o papel de cuidadora vem de longa data acompanhando as mulheres como se fosse natural essa obrigação e não algo aprendido, relacionado com a educação. No momento em que as mulheres terminam suas tarefas de cuidar dos filhos porque estes já se tornaram pessoas adultas, começam o cuidado com o pai e/ou mãe, Que dependem física ou psicologicamente delas. Se forem casadas ou tiverem companheiros, provavelmente estarão cuidando desses homens também, ou logo essa tarefa terá início em suas vidas, pois, para as esposas, o ato de cuidar está embutido no seu papel de mulher casada, a partir do compromisso assumido e selado desde o momento do matrimônio, no projeto de vida em comum. Como avós, desempenham o papel de apoio aos filhos e às filhas, cuidando dos netos.

Desse modo, a mulher Que já tem um vínculo social maior com o espaço privado, ao se engajar no papel de cuidadora da casa e da família, vê esse vínculo reforçado, o Que produz uma redução de sua participação no espaço público e, consequentemente, prejuízos para o seu bem-estar biopsicosocial, ou seja, estar circunscrita a esse espaço é estar privado da relação com os outros pela palavra e pela ação na construção das decisões concernentes ao mundo público, ou seja, à existência política ${ }^{(15)}$.

Já no concernente ao cuidar de si, as mulheres enfocam apenas o cuidado com a saúde, traduzido na atenção ao corpo, através de atividade física e alimentação adeQuada, além da procura regular 
de serviços de saúde, talvez por serem mais acostumadas a terem seus corpos medicalizados ao longo dos seus diferentes ciclos de vida, tornando-as mais expressivas Quanto à necessidade de autocuidado, condição pouco referendada pelos homens. Essa forma de cuidado compreende suas possibilidades de enfrentamento da velhice, visando minimizar ou retardar seus efeitos, o Que lhes assegura um sentimento de autoeficácia, sobreestimando o seu potencial físico, cognitivo e de sociabilidade.

A maior procura por serviços de saúde demonstrada pelas mulheres tem sido verificada em estudos realizados em diferentes contextos culturais, os Quais apontam diferenciais de gênero como base geradora de tal comportamento, pois as mulheres têm mais permissão cultural para expressarem Queixas de desconfortos do Que os homens, o Que poderia explicar o maior índice de diagnósticos tardios de alterações na saúde desses indivíduos, reduzindo suas possibilidades de melhora ${ }^{(17,18)}$.

Esse fato está associado à própria socialização dos homens, em Que o cuidado não é visto como prática masculina e, ao mesmo tempo, com as prescrições sociais Que representam o risco não como algo a ser evitado pelos homens, mas como algo a ser superado cotidianamente por eles ${ }^{(19)}$. Tal realidade aponta a necessidade de se refletir sobre a masculinidade para uma compreensão dos comprometimentos da saúde do homem.

Nesse contexto, o imaginário de ser homem pode aprisionar o masculino em amarras culturais, dificultando a prática de autocuidado, pois, à medida Que o homem é visto como viril, invulnerável e forte, procurar serviços de saúde ou evidenciar comportamentos de prevenção de doenças poderá aproximá-lo das representações do feminino, o Que implicaria, possivelmente, desconfianças acerca dessa masculinidade instituída ${ }^{(1)}$.

Ao discorrer sobre essa realidade masculina, sem negar a dominação dos homens, Giffin ${ }^{(20)}$ salienta Que estes são marcados e brutalizados pelo mesmo sistema Que lhes dá privilégios e poder. A concepção de "ser homem", a partir de vários prismas, outorga, de um lado, poderes e privilégios; de outro, é fonte de dor e de alienação, pela maneira com Que os homens interiorizam e reforçam esse poder ${ }^{(18)}$.

Desse modo, a equidade de gênero, no trato das questões relativas à saúde, perpassa as condições de acesso e utilização dos serviços. A alocação de recursos (tecnológicos, financeiros e humanos), bem como a abordagem dos profissionais devem seguir critérios diferenciais, conforme as necessidades de cada sexo. Implica Que homens e mulheres recebam, efetivamente, atenção de Qualidade, Que leve em consideração seu saber, seu fazer e seu modo de ser sobre seu corpo e seus processos, muitas vezes desvalorizados ante as relações de poder hierárquicas e assimetricamente situadas entre profissionais (saber científico) e clientes (saber popular), gerando práticas de saúde não aceitáveis ou não válidas ${ }^{(21)}$.

Também nos chamou a atenção, Quando as mulheres assumem em suas falas, a importância de se "comportarem como mulheres idosas", estando atentas especialmente às vestimentas e ao modo de se comunicarem: "ter uma conversa decente, conversa madura", sendo o corpo, portanto, o elemento enunciador da distinção entre o masculino e o feminino, tanto na sua dimensão física como na social.

O corpo é visto como um cabide de pé no Qual são jogados diferentes artefatos culturais, especificamente aqueles relativos [...] ao comportamento ${ }^{(12,22)}$. Neste caso, as mulheres jogam em seus corpos modos de ser do feminino Que, desde cedo, aprenderam no seu mundo social, onde a ideia coletiva é a de Que as mulheres, principalmente as idosas, devem conversar e também se vestir discretamente, impedindo a manifestação de suas características sexuais e individuais.

Os códigos sociais constituem o Que chamamos de mundo real - eles são introduzidos pela educação e servem para decodificar a gramática cultural. Desse modo, cada cultura modela e fabrica um corpo humano, seja por meio de razões sociais, seja por rituais ou apenas por razões estéticas ${ }^{(23)}$. A sociedade marcaria, assim, o corpo de seus membros na produção do Que serão as insígnias da identidade grupal.

Nesse cenário, o corpo feminino, objeto maior de regulação social, é, por conseguinte, contido ao máximo em suas ações. Como resposta a isso, espera-se Que toda essa contenção resulte, simultaneamente, em uma corporalidade delicada, um comportamento polido e um gestual estudado minuciosamente em seus movimentos.

No segundo momento da vivência grupal, Quando os homens e mulheres se posicionaram no sentido de apontar o Que o outro, do sexo oposto, na condição de homem ou de mulher, deveria ou não realizar, obtivemos, por parte dos homens, o seguinte material empírico: se eu fosse mulher idosa eu deveria...

...realizar ações voltadas para o entorno da casa e da família

- ser boa dona de casa, administrando bem os problemas da casa;

- cuidar dos filhos;

- ajudar o marido;

- não esquecia a família;

- ser compreensiva e carinhosa com o marido e com os filhos. ...realizar trabalhos próprios para a idade e para a mulher

- procurava trabalho voltado para a idade, fazia crochê, bordado, pintura;

- fazia curso [de culinária] só para idoso, para aprender mais a fazer a comida Que não prejudica.

Nas respostas frente ao item: se eu fosse mulher idosa, eu não deveria..., os homens idosos se posicionaram assim:

... ter práticas desaprovadas pelo referente masculino machista

- arrumar homem;

- viajar sem acompanhante;

- brigar com o marido;

- ter companhias duvidosas.

Quanto às falas evidenciadas pelas mulheres na completude da Questão: se eu fosse homem idoso, eu deveria..., verificamos:

... ser exemplo para a família

- ser um bom chefe de família;

- tratar bem minha esposa;

- ser mais companheiro com a esposa;

- não maltratar a mulher;

- ser espelho para os filhos;

- não "pular a cerca";

- ser um vovô muito bonito;

- casar apenas uma vez, para respeitar a mulher e os filhos.

... ser ativo sexualmente

- ter atividade no sexo; 
- namorar muito;

- conhecer várias mulheres;

- paquerar;

- tomar viagra para estar sempre em ordem;

- ser bem forte para fazer sexo;

- não deixar de namorar.

... ser mais livre

- ser independente das regras impostas pela sociedade;

- fazer mais amizades, passear mais, ser mais livre.

Dando continuidade ao assunto, as mulheres afirmaram Que, caso fossem homens idosos, elas não deveriam...

... abandonar a família

- deixar minha família;

- deixar a esposa por outra mulher.

... ter comportamento desaprovado socialmente

- fazer aquilo que fazia Quando novo, Querer ser novo sem ser;

- fazer nada de errado, fazer coisas Que não agradam a Deus;

- andar por caminhos perigosos;

- me expor ao ridículo;

- ser preguiçoso;

- gastar meu salário com farras, ser irresponsável.

Fazendo uma relação entre as falas dos homens e das mulheres, verificamos claramente Que ambos reivindicam para o outro comportamentos e papéis naturalizados por modelos, ideias e valores sociais, configurados a partir de oposições binárias, em Que se estabelece claramente o Que é ser masculino e o que é ser feminino, cabendo às mulheres, no geral, o exercício de papéis mais ou menos estereotipados, Que as colocam em posição de desvantagens em várias instâncias da sociedade.

Tal menção se ancora nos discursos apresentados, Quando os homens apontam para as mulheres a possibilidade de realizarem ações do mundo doméstico ou aquelas aprovadas pelo referente masculino e, ainda, Quando as mulheres ressaltam para os homens a importância de eles serem exemplos para a família, sendo especialmente "um bom chefe de família", bem como Quando salientam Que, na condição de homem idoso, poderiam "ser mais livres e ativos sexualmente", possibilidades que as mulheres negam a si próprias, talvez para fugirem do estigma de "velhas assanhadas", corroborando, assim, com as regras impostas pelo mundo masculino, tais como as explícitas pelos idosos: "não arrumar homem", "não ter companhias duvidosas" e outras.

A fala das mulheres sofre influência da identidade de gênero masculino, construída em tempos pretéritos, em que "ser homem" significava não estar marcado pela contenção. Já a linha de raciocínio organizadora do discurso dos homens idosos, expressa, em consonância com Bourdieu ${ }^{(24)}$, uma "somatização das relações de dominação", as Quais imprimem aos sujeitos dominados - no caso às mulheres determinados gestos, palavras ou marcas de sua submissão, imprimindo em seus corpos modos específicos de ser e de estar.

Com esse mesmo enfoque sobre a Questão, Louro ${ }^{(6)}$, subsidiada pelas ideias de Foucault, menciona Que homens e mulheres se fazem também através de práticas e relações Que instituem gestos, modos de ser e de estar no mundo, formas de falar e de agir, condutas e posturas apropriadas, isto é, nas e pelas relações de poder. Nesse contexto, há uma interpretação social das diferenças, uma moral Que as desenvolve e Que confirma o homem e a mulher no estatuto para o Qual estão designados ${ }^{(25)}$.

O discurso dos idosos reflete, então, a ideologia de gênero que permeou o seu processo de socialização, vivenciado nos últimos cinquenta anos do século passado Que permitiu a construção das identidades de homens e de mulheres a partir da atribuição de papéis, atitudes e valores previamente definidos segundo modelos naturais, gerando estereótipos acerca de masculinidade e de feminilidade.

Além do exposto, estudos psicossociais indicam Que as primeiras influências recebidas do social e da cultura são as mais arraigadas ${ }^{(4)}$. Talvez por isto, mesmo os idosos experimentando relações de poder homem/mulher Que, no decorrer de suas trajetórias de vida, foram se alterando de uma nítida assimetria relacional até relações mais próximas e simétricas, eles vêm mais assistindo a elas do Que delas participando, propriamente.

Retomando ainda à fala das mulheres idosas, realçamos o sentido de velhice estigmatizada, impregnada em seu imaginário, Quando estas salientam Que, caso fossem homens idosos, não deveriam "fazer aquilo que faziam Quando novo", pois haveria o risco de se "exporem ao ridículo". Tais menções, no nosso entendimento, evidenciam, além de preconceitos naturalizados relativos à velhice, as desigualdades das relações sociais de gênero vividas pelas mulheres, tornando-as mais facilmente adaptáveis às sanções advindas do sistema sócio-cultural, especialmente aos mais velhos.

\section{CONSIDERAÇÕES FINAIS}

Ante o exposto, ressaltamos Que o entrelaçamento entre a perspectiva de gênero e velhice permite o entrecruzamento entre essas dimensões nas experiências subjetivas. Isto Quer dizer Que os valores e padrões sociais e culturais construídos pela sociedade estão presentes no dia a dia dos idosos pesquisados e influenciam o comportamento e as atitudes dessas pessoas, na medida em Que determina como deve ser o masculino e o feminino na velhice.

No concernente aos papéis sociais de gênero na velhice, atribuídos pelos idosos, apreendidos a partir da auto e da heteropercepção, do olhar de si e do olhar do outro, observamos Que estes se estabelecem a partir das relações efetuadas entre os domínios do público e do privado, Que obedecem à divisão de especialidades entre o universo masculino e o feminino, sendo o masculino associado ao mundo público e, em contrapartida, o domínio da casa foi representado como feminino por excelência. Os homens e mulheres participantes deste estudo se apoiam numa visão de mundo em Que demarcações entre os gêneros são nitidamente circunscritas a partir de características de períodos passados, mesmo que de forma mais atenuada.

\section{REFERÊNCIAS}

I. Gomes R, Nascimento EF, Araújo FC. Poreue os homens buscam menos os serviços de saúde do Que as mulheres? Cad Saúde Pública 2007; 23(3): 565-74.
2. Labourie A, Locoh T. Genre et demographie. Paris: Dossiet et Reherches; 1999. 
3. Trindade E, Bruns MAT. Meia idade masculina: significados do envelhecimento. In: Bruns MAT, Del-Masso MCS, organizadoras. Envelhecimento humano: diferentes perspectivas. Campinas: Alínea; 2007. p. 35-52.

4. Negreiros TCGM. Sexualidade e gênero no envelhecimento. Alceu 2004; 5(9): 77-86.

5. Figueiredo MLF, Tyrrel MA, Carvalho CMRG, Luz MHBA, Amorim FCM, Loiola NLA. As diferenças de gênero na velhice. Rev Bras Enferm 2007; 60(4): 422-7.

6. Louro GLL. Gênero, sexualidade e educação: uma perspectiva pós-estruturalista. $9^{\mathrm{a}}$ ed. Petrópolis: Vozes; 2001.

7. Laurentis T. A tecnologia do gênero. In: Holanda HB, organizadora. Tendências e impasses: o feminismo como crítica da modernidade. Rio de laneiro: Rocco; 1994. p. 206-42.

8. Ministério da Saúde (BR). Conselho Nacional de Saúde. Diretrizes e normas regulamentadoras da pesQuisa envolvendo seres humanos: Resolução no 196/96. Brasília (DF): Ministério da Saúde; 1996.

9. Militão A. SOS dinâmica de grupo. Rio de janeiro: Qualitymark; 2002.

10. Fiorin JL. Elementos da análise do discurso. $13^{\mathrm{a}}$ ed. São Paulo: Contexto; 2005.

1 1. Silva MTN. A desigualdade de gênero na terceira idade. Terceira Idade 2006; 17(36): 32-8.

12. Heilborn ML, Carrara S. Em cena, os homens... Rev Estud Fem 1998; 2: 370-74.

13. Heilborn ML. Articulando gênero, sexo e sexualidade: diferenças na saúde. In: Goldemberg P, Marsiglia RMG, Gomes MH, organizadores. O clássico e o novo: tendências, objetos e abordagens em ciências sociais e saúde. Rio de Janeiro: Fiocruz; 2003. p. 197-208.
14. Neri AL. Feminização da velhice. In: Neri AL, organizadora. Idosos no Brasil: vivências, desafios e expectativas na terceira idade. São Paulo: Fundação Perseu Abrano; 2007. p. 47-64.

15. Guedes N, Silva ATM, Coelho EAC. Violência conjugal: problematizando a opressão das mulheres vitimizadas sob o olhar de gênero. Rev Eletrônica Enferm 2007; 9(2): 362-78.

16. Barros MML. Testemunho de vida: um estudo antropológico de mulheres na velhice. In: Barros MML, organizadora. Velhice ou terceira idade? Estudos antropológicos sobre identidade, memória e política. Rio de Janeiro: Fundação Getúlio Vargas; 2007. p. 113-68.

17. Barreto SM, Giatti L, Kalache A. Gender ineeualities in health among Brazilian older adults. Pan American J Pub Health 2004; 16(2): 110-17.

18. Paschoalicck RC, Lacerda MR, Centa ML. Gênero masculino e saúde. Cogitare Enferm 2006; I I (1): 80-6.

19. Costa RG. Saúde e masculinidade: reflexões de uma perspectiva de gênero. Rev Bras Estudos Popul 2003 20(1): 79-82.

20. Giffin KA. A inserção dos homens nos estudos de gênero: contribuições de um sujeito histórico. Cien Saúde Coletiva 2005; 10(I): 47-57.

21 . Fonseca RMGS. Equidade de gênero e saúde das mulheres. Rev Esc Enferm USP 2005; 39(4): 450-9.

22. Nicholson L. Interpretando o gênero. Rev Estud Fem 2000; 8(2): 9-14.

23. Novaes IV. O intolerável peso da feiúra: sobre as mulheres e seus corpos. Rio de Janeiro: Garamond; 2006.

24. Bourdieu P. A dominação masculina. Rio de Janeiro: Bertrand Brasil; 1999.

25. Le Breton DA. A sociologia do corpo. 2a ed. Petrópolis: Vozes; 2007. 